\title{
Thormation
}

Nordic Journal of Art and Research

ISSN: $1893-2479$

www.artandresearch.info

\section{Negotiating the Image of the City: \\ A Discussion of Skilled Perception and the Role of the Artist in the Redevelopment of Bjorvika}

\author{
Charlotte Blanche Myrvold ${ }^{1}$ \\ Oslo and Akershus University College of Applied Sciences
}

\begin{abstract}
In the master plan of the redevelopment of the former industrial harbor Bjørvika, funding for art is stipulated along with access to the site during the construction phase. This article looks at an intervention, from 2005, of the artist Marianne Heier, in relation to the strategic use of imagery in place branding and the use of images to structure change. The epistemological dimension of images will be argued to have ontological implications on how we perceive the world and consequently act upon it. This article suggests the need for a critical approach to mediated images in the context of urban development. By discussing the relationships between Lorraine Daston's use of the notion of 'skilled perception' and Jaques Rancière's concept of the 'distribution of the sensible', I attempt to draw attention to how our perception is skilled and thus affects what we hold in common. Ultimately, the formation of public spaces is the subject of the article and by pointing to the role that images play, as the way we see the city is shaped, this paper argue the need for images that unveil otherwise unrepresented potentials and interests. The notion of skilled perception is presented as a tool for investigating how mediated images in Bjørvika form the basis of perceptual habits, and are suggested to be of use in grasping the "politics" of artistic interventions within the larger constructed image of Bjørvika.
\end{abstract}

Keywords: Public art, public space, urban redevelopment, skilled perception, Bjørvika, Marianne Heier, image, perceptual regime, place production, observation, cloud, waterfront development, critical art, seeing collective

\footnotetext{
${ }^{1}$ Departement of Art, Design and Drama, Oslo and Akershus University College of Applied Sciences, PB 4, St. Olavs Plass, N-0130. E-mail: charlotte-blanche.myrvold@ hioa.no
} 
From the perspective of anthropology, we are not the masters of our images, but rather in a sense at their mercy; they colonize our bodies (our brains), so that even if it seems that we are in charge of generating them, and even though society attempts unceasingly to control them, it is in fact the images that are in control. (Belting, 2011, p.10)

\section{Introduction}

This article addresses the ongoing redevelopment of Bjørvika, the former industrial harbor, in Oslo. Bjørvika can be seen as part of a global trend known as waterfront development. The attempt to attract transnational capital and exploit lifestyle, leisure, and culture as a means to brand the place is characteristic of this type of urban development. Rendering assets visible is a major part of the branding of such places.

A prime consideration of urban development is founded in the concept of the material redistribution of space; however, the importance attributed to the imageability of the place in Bjørvika, is a distribution of another order. Here, I suggest that the involvement of the redevelopers in the production of an image of Bjørvika influences the sensory landscape, and can be understood through the philosopher Jaques Rancière's concept of a distribution of the sensible (Rancière, 2000, pp. 12-14). This notion identifies how our partition in the sensible is formed through the configurations of time and space, work and leisure, private and public, which play out quite literally in the context of the redevelopment of Bjørvika. By emphasizing that, the sensible is something in which we partake and the distribution of the sensible is a configuration of what a community holds in common, the sensible is outlined as shared dimensions of time and space to which our access is limited and must be negotiated.

Specifically, the access to a position from which one is seen and heard, and the access to a position from which one can see and hear are political; nevertheless, our partition of the sensible is also the configuration of a shared way to perceive the sensible. I want to investigate how the production of the imagery of Bjørvika is a means of configuring the sensible and a locus for negotiating the experience of the sensible, as well as the constitution of the public.

One might argue, as has the philosopher Gernot Böhme (1998), that the prevalence of vision over other senses in urbanistic interpretations of place necessitates other perceptual approaches. Although I adhere to this perspective, I also think a critical approach to the role of vision is equally important. Therefore, this paper investigates how and what the constructed image of Bjørvika encompasses. My focus is to delineate a relation between the construction of images and spatial production through the intermediate mediation of perception. This paper additionally attempts to outline the possibility for opening new forms of visibility in the public, as counterparts to the stage value, which dominates the constructed appearance of cities (Böhme, 2008, p.528).

As pointed out by urban geographer Heidi Bergsli, in her analysis on the entrepreneurial city development-model applied in Bjørvika, the striking and seductive visuality of waterfront 
developments simultaneously draws attention away from other areas of the city and contributes to the spread and mimic of the waterfront development model around the world (2005, p.112). While art historian Hans Belting's definition of image provides a starting point for grasping the cultural diffusion of images, it also informs my use of the word. Belting dissociates image and medium and determines the medium as the specific kind of materiality, which, in each case, renders the image visible. Although the medium can be a painting or a photo, when the image is lodged into the memory, the body becomes the medium (Belting, 2011, p.44). While the images have a nomadic character, the medium, the body, is a carrier of those images (Belting, 2011, p. 21). Indeed, the understanding of an image as nomadic captures the mobility of that image and its transgression into different mediums. In the context of the waterfront development of Bjørvika, one can recognize a generic image that has traveled worldwide. Nonetheless, the concern of this paper is to explore how the image travels from one medium to another and is incarnated in the city. I will present two computer-generated images of Bjørvika, made for planning purposes, and contrast them with an intervention by the artist Marianne Heier. I will discuss Heier's work as potentially rendering previously unperceived forms of visibility. An understanding of perception as skilled, and therefore theoretically evolving, is central to this reading. I suggest that it is by being plastic that perception plays an important role in the distribution of the sensible and I will attempt to support this assertion by presenting relationships between the work of Rancière and Daston on the ontological dimension of perception and the constitutive part it plays in relation to the formation of the public.

\section{Skilled Perception and the Configuration of the Public}

We see the world differently, depending on profession and culture. ${ }^{2}$ The term skilled perception describes those qualities of seeing and understanding that are developed within a profession or a specific community. A skilled perception is attained in the same manner as all other skills; through trained practice. The notion of "skill" reflects the increase in knowledge that occurs as the practice is trained. As the sociologist Richard Sennett argues, there is an ancient tie that joins skills and community and from this tie, the collective agent of craft is established (2008, p.51, 73). The development of skilled perception is not merely a process that plays out between the subject and the perceived object; it unfolds through the subject's participation in a collective. Skilled perception denotes a relational aspect of perception that is said to be tacit and, consequently, is frequently omitted or excluded from discourse. I suggest that skilled perception has an agency based on the constitution of a common experience. More specifically, it influences spatial practices that contribute to the formation of common ground. I wish to investigate the role of images in the training of perception and suggest the agency that artists can have on the formation of common perceptions of a given phenomenon.

\footnotetext{
${ }^{2}$ See Grasseni, C., Ed. (2007). Skilled visions: Between apprenticeship and standards. New York, Berghahn.
} 
Science historian Lorraine Daston investigated the collective conditions of one of the prime examples of skilled perception, namely scientific observation. Daston argues that perception is trained through repetition and that the role of habit is determinative as to which objects are perceived as stable, universal, or scientific objects; furthermore, this has ontological implications.

Without these acquired habits of perception cultivated by observation, there would not only be no science; there would be no articulated visible (or auditory or tactile) world at all. This is the way perception furnishes the universe. It doesn't create the universe, but it does shape and sort, outlining sharp edges and arranging parts into wholes. In contrast to languages, which may be learned either by ear or by grammatical rules, there seems to be only one route to competent perception, and that royal route is habit. (Daston, 2008, p.100)

In the citation above, the role of skilled perception, arranging the universe into parts and wholes is poetically described as a way of furnishing it. Although distinguishing language and perception, the argument suggests that it is only by being skilled and competent that perception can articulate the world and form the basis of a collective way of seeing and holding the world in common. If one considers the ontological implications of this assertion, the arrangements of parts and wholes through which we articulate the world, is a bilateral movement in which the world is shaped, both by the slow skilling of perception as well as in the way skilled perception resonates in the construction of the physical world. Brita Brenna, historian of ideas, exemplifies such that it is only possible to perceive a terrain as a landscape if one have learned to do so. By establishing a connection between the findings of Daston and the conception of the landscape, Brenna manages to demonstrate how perceptions of landscape are intimately connected with economic and politic changes in our relation to it, and ultimately forms how we act upon it (2012, p.14).

I propose that there is a strong affiliation between Daston's use of the notion of skilled perception and Rancière's description of the formation of perceptual regimes. Rancière does not use the notion of skilled perception, nevertheless one could say that it is an element of his thought. It is present when he describes the writer Stendhal's “éducation sensible” (2004, p.14), fiction's ability to change our perception (2008, p.72), and the correlation between emancipation and new ways of perceiving $\left(2008\right.$, p.26, 49), which is central to his theory of the reconfiguration of the sensible. ${ }^{3}$ In his writings on the politics of art, Rancière discusses art in relation to the production of new forms of visibility and reconfigurations of perceptual regimes through new ways of sensing (manières de sentir). ${ }^{4}$ It is through reconfigurations of this type that art and politics touch upon each other as forms of dissensus (Rancière, 2008, p.55). ${ }^{5}$ Therefore, the politics of art can be said to consist of the

\footnotetext{
${ }^{3}$ An on-going topic in Rancière's writing from La Nuit des prolétaires. Archives du rêves ouvrier of 1981 to his newer texts.

${ }^{4}$ See: Les paradoxes de l'art politique (Rancière, 2008), L'esthétique comme politique (Rancière, 2004), and The aesthetic revolution and its outcomes (Rancière, 2010).

${ }^{5}$ Rancière plays with the ambiguity of the notion of consensus and defines it as the accordance of "sens and sens"; signification and perception (Rancière, 2008:75). Dissensus is an operation linked to art, while perceptual
} 
suspension of the coordinates of the ordinary experience of the sensible (Rancière. 2004, p.39). This outlines the potential of art to produce new visible forms by the operation of dissensus and suspension; nonetheless, these forms should not be taken literally, as it is as much a form of perception as the perception of a form.

As far removed from each other as the symbolist poet and the functionalist engineer may seem, they both share the idea that forms of art should be modes of collective education. Both industrial production and artistic creation are committed to doing something on top of what they do - to create not only objects but a sensorium, a new partition of the perceptible. (Rancière, 2010, p.122)

Discussing the utopian quest for an aesthetic revolution, Rancière mentions the interest of artists and engineers in the idea of a collective education. ${ }^{6}$ In the comment above, he clearly distinguishes the creation of an object and the creation of a sensorium; differentiation of the two enables us to notice the plasticity of perception and its receptivity to the forms of art.

\section{Seeing in Unison}

I now propose a little detour into the history of observation of clouds for the purpose of presenting the notion of seeing collectives and their relation to images. In the article "On Scientific Observation", Lorraine Daston presents an example of an everyday object that posed tremendous challenges to the scientific community's definition of it as a scientific object. That object was clouds.

The International Cloud Atlas of 1896 was meant to make clear-cut scientific objects out of evanescent, protean clouds by teaching observers all over the world, on land and at sea, to see things in unison. (Daston, 2008, p.104)

Since clouds are a global phenomenon, such a synchronization of visions would imply that observers all over the world would be able to discern the same universals, despite the multitude of shapes in which clouds appear. The consequence of the global scope of the research was that the collective of observers, both scientist and lay people, would have to agree on what they saw and what to call it, in spite of geographical and linguistic differences. Therefore, the linking of image and word was pivotal in the effort to reach a collective agreement of what was seen. In the case of clouds, the International Cloud Atlas played a crucial role in providing a common ground from which the collective could practice seeing in unison. It is said that none of the meteorologists where allowed to leave Uppsala before this collective vision was formed. Seeing the same would entail having the same competence, or if one follows the point Daston makes on habits, the collective would have to learn to see the same by repeating the same observations. Good perceptual habits are learned as students gradually learn to

regimes, in contrast, are characterized by consensus, a proper order of configuration of the sensible (Rancière, 2010, p.213).

${ }^{6}$ On engineers' agency on the shaping of new sensorium, see Gjesvik, T. På sporet av veier i 1800-tallets Voyages pittoresques. In (Eds) Kampevold Larsen, J. \& Frang Høyum, N. Utsikter sett fra veien 1733-2020. Oslo, Forlaget Press, and Picon, A. (1992). French architects and engineers in the Age of Enlightenment. Cambridge, Cambridge University Press. 
see the same thing and in the same way as their masters. In paraphrasing the bacteriologist and philosopher Ludwik Fleck, Daston shifts the focus from "thought collectives" to "seeing collectives," and thus describes how scientists are trained to share ways of seeing (2008, p.106). To articulate the relationship between images and the skilling of perception, I wish to elaborate on the notion of seeing collective, as presented by Daston. In the case of clouds, the global reach of the phenomenon, the shifting conditions of the observations, and the infinite variety of forms, offered a demanding condition for a systematic shaping of perceptual habits through repetition. This is also why the 28 templates in International Cloud Atlas, which the collective of meteorologists agreed upon, was of such tremendous importance. The way clouds were rendered was a significant factor in the training of the perception of clouds.

\section{Image as a Tool to See Better}

The role and agency that art, through image-making practices, have had in science is extensive; clouds are only one of many possible examples. ${ }^{7}$ In the first International Cloud Atlas, published in 1896, the Danish artist and librarian Philip Weilbach contributed depictions of clouds. By close observations of the sky, he later identified a new type of cloud, the cumulonimbus, a thunder cloud. Similarly, by linking word and image, the artist John Constable's depictions of clouds contributed to stabilizing the new categories that ordered the mutable clouds. The new taxonomy of clouds found its visual expression in the art of its period. Since observations are transitory in nature and a situated experience, which is not easily repeated for the many, images play an important role as containers and conveyers of multiple and dispersed data. Daston writes that the ambition of innovative visualization techniques is to condense the findings so that one can view it in one 'coup d' $x i l$ ' as an experience of all-at-onceness (2008, p.108). As part of her conclusion, she claims:

It is observation, grounded in trained, collective, cultivated habit, that fuses these bits and pieces into a picture-often a literal picture crafted by techniques of scientific visualization. And it is the picture, seized at a glance, all at once, that guarantees the sturdy existence of a world (Daston, 2008, p.110).

The image is attributed a role as container of a certain warranty in which the seeing collective can ground their consensus and expand the collective through developing skill in perception. As she identifies the formation of a scientific seeing collective, Daston indicates a relationship between perception, image, and participation in a collective. By looking closely at the role that images play as skill in perception is developed, one can define skilled visions in relationship to skilled perception.

\footnotetext{
${ }^{7}$ Three examples are Jones, C. A., Galison, P., \& Slaton, A. (1998). Picturing science, producing art. New York: Routledge, Klonk, C. (1996). Science and the perception of nature. British landscape art in the late eighteenth and early nineteenth centuries. London: Yale University Press, and Daston, L., \& Lunbeck, E. (2011). Histories of scientific observation. Chicago: University of Chicago Press.
} 
This notion seeks to identify skills that are trained by the help of visualizations, which point to the qualities that are important within the "seeing collective" to which one belongs. ${ }^{8}$

I suggest that skilled vision can be read in a triangular relation to the collective on one side, and the mediated visualization on the other. This triangular constellation entails that each part relies on the other two; the collective needs the mediated image to externalize a common understanding of what they see, the mediated visualizations play upon the formation of skill, and the skill is the ticket to participation in the collective. The purpose of the triangular schema is to articulate the collective character of skilled visions.

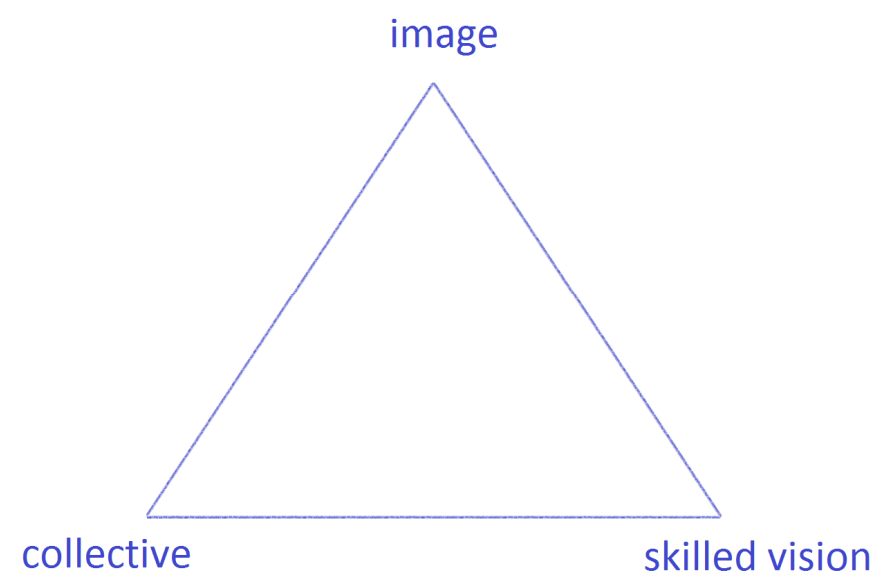

The relational aspect of perception is also outlined by Rancière, who articulates the partition in the sensible as belonging to a particular sensorium (2004, p.44) and investigates the collective function (fonction communautaire) of art as a constitutor of both common symbolic and material territories (2004, p.35). It is noteworthy that while Daston identifies the role that the images of clouds had as a new consensual way of seeing them, Rancière understood art as a practice that produces dissensus within an established regime of perception. Nonetheless, while the practices might sound as though they are in opposition, both theorists investigate changes in the way of seeing that destabilize an established ontological understanding of a phenomenon. Such reading would imply that Daston's study of the science of clouds is in fact pointing to a moment of dissensus and that the identification she does of scientific seeing collectives could very well articulate not only a relational aspect of perception, but also say something about the relationship between an acquired perceptual skill and changes in an entire perceptual regime. Therefore, seeing collectives could inform an analysis of what in Rancière's terms would be identified as clashes between perceptual regimes.

\footnotetext{
${ }^{8}$ Specifically, skilled visions are not merely a result of direct perception of the "live" phenomenon, since mediated images of the phenomenon play a role as one learns to recognize the qualities represented in the image.
} 
My concern in the context of Bjørvika is the construction of its image and the stakeholder's desire for visibility. The notion of skilled perception is a tool for investigating how mediated images in Bjørvika form the basis of perceptual habits and "collectives of seeing," but might also be of use in grasping the "politics" of artistic interventions within the larger constructed image.

\section{The Image of Bjørvika as a Perceptual Regime}

Visuality plays an important role in Bjørvika. Because of its early commitment to a cultural planning strategy, the redevelopment of the former industrial area is unique in a Norwegian context. However, the "Supervisory Program for Culture" (Kulturoppfølgingsprogrammet, in short the KOP-document), an appendix to the master development plan of 2003, attributes a cultural role that is largely defined in relationship to sight and visuality. One of the major recommendations of the KOP-document is to strategically invest in cultural activities to make Bjørvika visible both locally and internationally. The desire for visibility is part of the place marketing strategy embedded in the KOP-document, and culture is partially defined as a dimension of the brand that is being constructed. Specifically, the KOP-document is imbued with the intention of constructing a cultural image. What the difference might be between a cultural image of a place and a cultural place, or how one should deal with the construction of visibility pursued through culture in Bjørvika, are both questions that confront us with the ubiquitous presence of images and the agency of visibility in the production of place.

Whereas visual terms denote the branded image of the place, the KOP-document also refers to the sense of sight, or their vision, in relation to the stakeholder and the municipality's ambitions for Bjørvika. While an effective marketing image is characterized as simple, ${ }^{9}$ the vision is described as a strategic tool for building a sustainable city and the goals are to encompass diversity. The vision of Bjørvika's goals is to include history, modernity, technology, the environment, and an idea of the Norwegian, as well as all the inhabitants of Oslo. Consequently, it is recommended that the process of producing a vision be wide in scope (Plan- og bygningsetaten et. al., 2003, p.11). The strategic construction of both vision and image is particularly interesting because both the stakeholders and the municipality rhetorically underscore it as an important area in which to invest during the actual physical construction of the site (Plan- og bygningsetaten et. al., 2003, p.15). Specifically, the visibility of Bjørvika is constructed and mediated independently of the conditions imposed by time and space on the actual place; to put it differently, the visibility of the site does not rely on its physical existence. This has yet to come into being. The strategy appears to be in the attempt to construct a well-directed visibility, established before the developed and completed Bjørvika enters the stage.

\footnotetext{
${ }^{9}$ Simplicity is one of five criteria for the design of a place's image; the others are validity, credibility, appeal, and distinctiveness (Kotler, Asplund, Rein, \& Haider, 1999, p.167).
} 


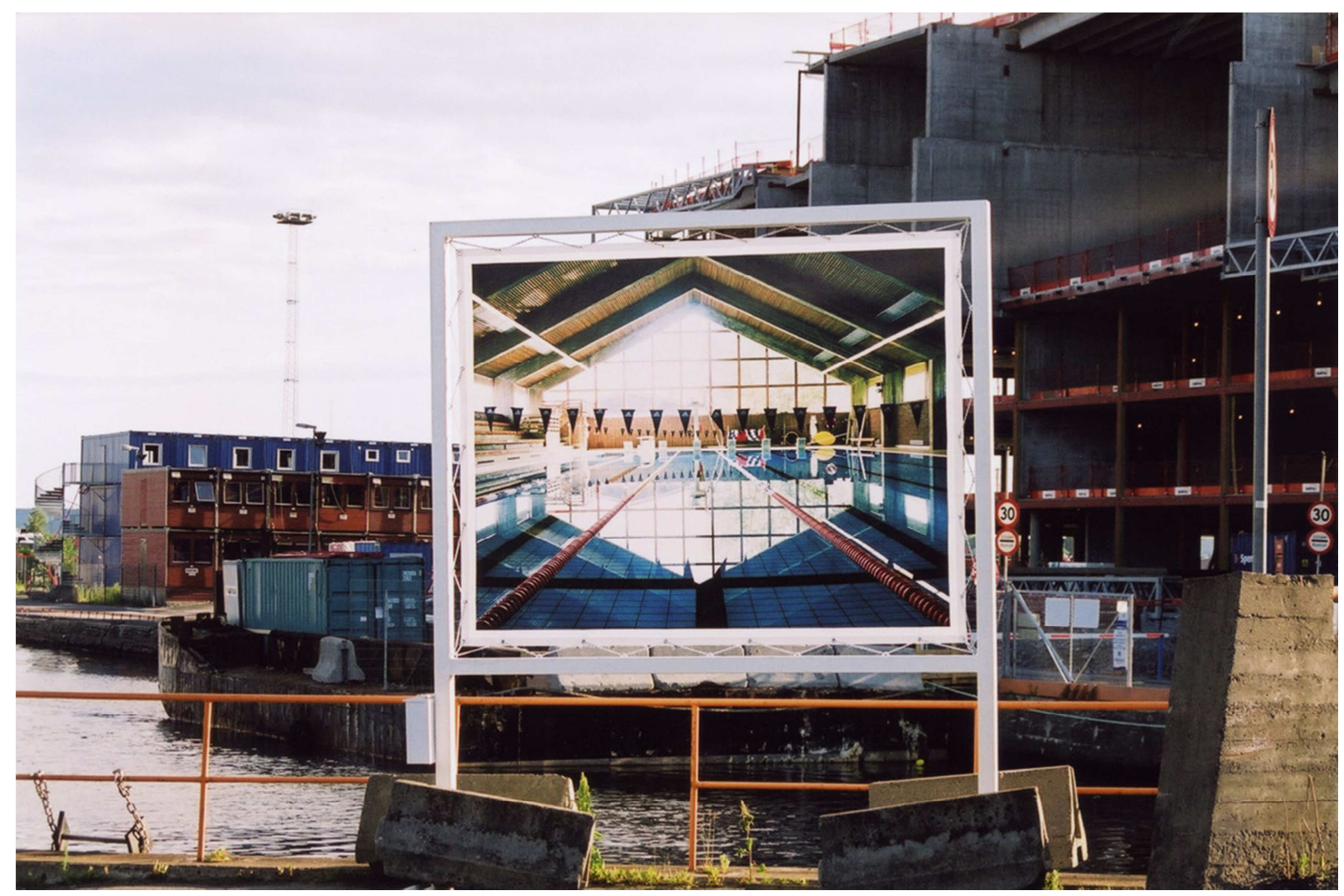

Marianne Heier, A drop in Ocean (2005). Note the placement of the image in relation to the physical construction site.

I believe that the aesthetic dimension at play in the image making strategy built to make Bjørvika visible is not only a question of how it looks, which would be a narrow understanding of aesthetics limiting it to a question of taste, but also a question of what is seen. It could well be said that the use of imagery for implementing positive connotations of Bjørvika in the public could be an attempt at constructing a "regime of visibility" in Jaques Rancière's sense of the term. In the case of Bjørvika, the economically strong classes targeted by the developers contrast the multicultural demography and the relatively high percentage of low-income families in the neighboring areas of Bjørvika, the inner east Grønland and Gamlebyen. Since the new public places of Bjørvika are to serve both groups, these social and economic differences are indeed important. Therefore, the vision of Bjørvika is sketched in various ways to represent very different interests to different members of the public. Although the two approaches to the visual in the KOP-document, namely the image and the vision, are argued to be fruitfully reflecting on each other, they are more likely to operate similarly concerning what is made visible. Consequently, the investment put into constructing a certain visibility is necessarily the product of layers of invisibility.

Graeme Evans, Professor in Urban Cultures, critically analyzed the consequences of imagebuilding strategies within contemporary urban development. He points out that one of the inherent objectives of branding strategies is to "create a unified version" of the product, and that this conflicts with the social and cultural complexity of space (2006, p.202). Moreover, divergent social and cultural interests are at stake, as one constructs an image that revolves around a coherent narrative. He warns 
that the strong impact of branding strategies, in the name of cultural planning, can produce uneven and unpredictable results of which spatial planning and more democratic city development have better tools to handle. Specifically, image-building raises the issue of representation. Who is represented in the constructed image? In the process of building a distinct and attractive image, there is a risk of masking and disregarding social and cultural aspects of a place by rendering them invisible.

The difference between image-building and the composition of an embodied and empirically experienced view is formulated by Hans Mommaas, who has written on the relation of city branding and contemporary architecture in the Netherlands. He describes one of the characteristics of city branding as, "The tendency to gear city brands to the dynamic of an external cash-rich marked rather than to that of internal cultural practices and feeling" (2002, p.198). The work of distance is evident both in the choice of images, which are easily mediated, as well as in the external forces that drive the marketing process. The consequence of branding places to attract international attention is that they become increasingly "constructed for the eye" (De Paoli \& Gran, 2005, p.175). However, the eye in question is not an eye that is embedded in the constructed site. Anne Britt Gran and Donatella De Paoli maintain that because they are skilled in producing visualizations, the emphasis on the place as a visual phenomenon favors the profession of architects, designers, and marketers in the place-branding processes. In the case of Bjørvika, there is a particularly explicit example of the agency of the mediated image on the development. Commenting on the design of the projected Munch museum, the architect Herreros said, "We are consciously designing the postcard everybody wants." ${ }^{10}$ What he pinpoints in this statement is to what extent the imageability of the building is its competitive strength. Moreover, the allusion to the postcard that "everybody" wants also addresses the efficiency of images already known and easily recognized. In other words, this type of image conforms to our habits of perception. However, the consequence of such imagery can be that place itself is rendered invisible through the striking and traveling imagery. As Evans maintained, the strategic use of image-building is a challenge to more democratic traditions of city development (2006, p.213). Nevertheless, it appears that there is a need for images to structure, imagine, and implement changes in physical environments. Visualization skills will have agency in relation to how urban environments are perceived and acted upon.

\section{Image and Spatial Production in Bjørvika}

While they are among the least accessible, the most influential visual representations of Bjørvika are probably the 3D models, which have been active tools in regulating the work in the area. By virtue of being a model of the site, the image constructed in the model is obviously ahead of the actual physical construction of the site and the model's purpose is to propose images that will later be implemented physically. Nevertheless, due to the strong impact of the visual, the 3D model permits one to

\footnotetext{
${ }^{10}$ Retrieved October 29, 2013 from http://www.arcspace.com/features/herreros-arquitectos/munch-museum/
} 
concretize how visualization skills have agency upon place production. In his article, "Bjørvika. Bruk av 3D i planarbeidene," the engineer, Torbjørn Tveiten, describes the efficiency of the 3D model in structuring such a large and complex construction as Bjørvika. The 3D model allows one to circulate the virtual Bjørvika and take snapshots from any location in the model; this is one of the possibilities that Tveiten puts forward as a valuable method of visualizing what otherwise could not have been seen; for instance, how the new high-rises would alter the view (2011, p.237). However, the design of the 3D model has also had an apparent and unexpected effect: In 2010, a new tunnel system was inaugurated underneath the bay of Bjørvika.

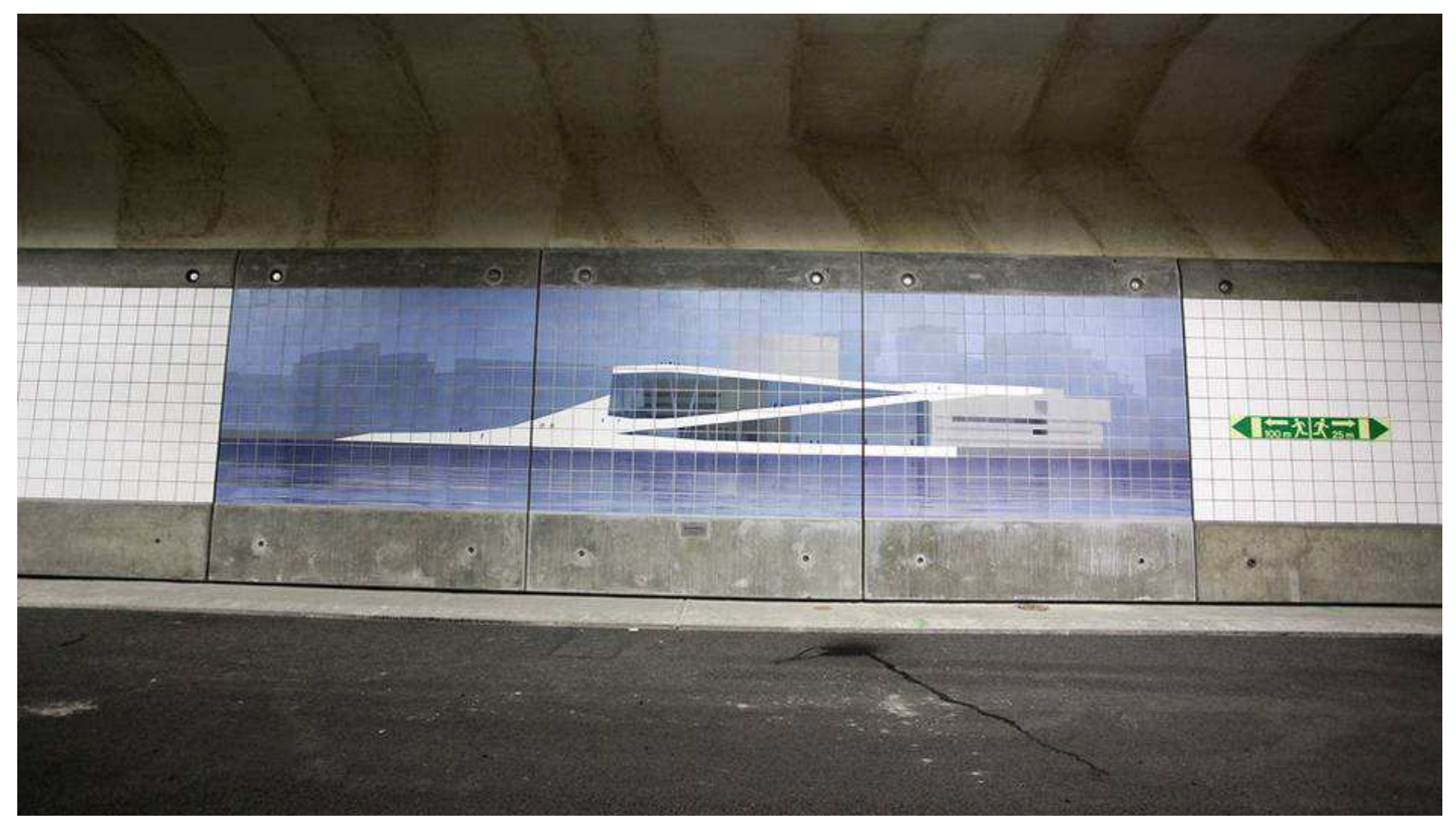

Photo taken by Mona Strande / Teknisk Ukeblad

During this period, the 3D model was in active use. Tveiten mentions what he describes as a mere curiosity; in the model, a picture of the National Opera and Ballet was inscribed on the tiles, this virtual decoration was later built in the actual tunnel (2011, p.238). One can imagine that the picture was originally meant to help make the monotone, virtual space of the tunnel legible and to differentiate the south going track from the other. Later, it can have been judged as adequate to realize this design in physical space. ${ }^{11}$ Nevertheless, a certain slippage took place, as an image that was originally meant only for the virtual representation of Bjørvika, leaked into the real world. From the account of Tveiten, there does not appear to be any particular reason or interest that drove the realization of the image on the tiles. Rather, there appears to be a certain innocent causality, which

\footnotetext{
${ }^{11}$ In Oslo, there have been antecedents of the practice of depicting a monument in a tunnel to inform the drivers of their location, e.g., the depiction of the Akershus Castle in the "Festningstunnelen." For the sake of the above argument, I want to emphasize that even a depiction of the opera can be done in a number of ways.
} 
resulted in the current decoration on the tiles. ${ }^{12}$ Of course, the tunnel could have been decorated in a number of ways, and one might object that this should be the task of professional artists. However, the way in which the picture of the opera came to decorate the walls of the tunnel illustrates how influential visualization skills are in the production of place.

Coming from the artistic field, not urbanism, what strikes me is the complexity of both time and space in the redevelopment of Bjørvika. Nevertheless, the outside perspective also manifests to what degree images and the visual appears to play different roles in this field, as compared with the artistic field. While images are always complex and visuality is never simple in art, in urban development, images seem to have one major function, and that is to solve complexity. To render it, art-based approaches to images frequently intend to disclose complexity, one might even argue that such attempts are a force that have provoked changes throughout the history of art. A comparison of the two approaches, solving or disclosing complexity through the media of images, might be best conducted if one named the sort of complexity with which one deals. In the case of 3D modeling, there is an obvious need to structure the changes and develop visualizations that resolve complex spatial scenarios. However, when images deal with complexity of a social and human order, it is timely to ask whether social complexity can actually be solved in an image, or are they merely concealed. The illustrations in the public space program of Bjørvika, conceived by Gehl Architects, ${ }^{13}$ approach the social complexity of public space in such a way that layers of visibility appear to be rendered at the expense of other aspects that are kept invisible. The illustration of one of the future public spaces, presented on the webpage of Bjørvika Development, Loallmenningen, is characteristic of the imagery being produced. The illustration displays people lingering in the public space, sitting around some sort of fountain, one person actually in the water. Others are passing by, some alone and others in groups, there is also a bike in the picture. In the distance, there seems to be a ball game going on, and the biker is walking. It might indicate that this place is so pleasant that there is no reason to hurry past. The "Loallmenningen" appears to be a place where people will gather, and the pivotal axis of success, highlighted repeatedly in the development plans of Bjørvika, is truly met in the image: the public spaces are teeming with city life. In the article "Oslo - The Triumph of Zombie Urbanism," urban theorist, Jonny Aspen, discusses the use of images in the public space program. Contextualizing the production of attractive urban imagery in relationship to place-marketing in urban redevelopment, Aspen argues that the public space program's staging of places, as diverse and vibrant, contributes to legitimizing the redevelopment. He suggests that through the visualization methods in urban design, the social challenges are presented as solved and thus the discipline is given a new role as legitimizing authority (2012, p.3). The problem Aspen identified within the public space program is that it

\footnotetext{
12 “Som en kuriositet kan det nevnes at det i sørgående løp midt i tunnelen vises Operaen på flisene. Grunnlaget ble her hentet fra 3D-modellen og benyttet direkte i produksjonen" (Tveiten, 2011, p.238).

${ }^{13} \mathrm{Gehl}$ Architects designed the master plan for the public space program, but the visualizations of the future commons were made in collaboration with different landscape architect offices.
} 
Myrvold: Negotiating the Image of the City

generally based on features and factors that can be quantified and mapped. However, the approach to social aspects of the public spaces is evasive and uncommitted (2012, p.11). One could say that what the program does not explain and exemplify, the images can be telling, however, for the imagery to be more than rhetorical figures of eloquence, they would have to contain empirically based knowledge, in the same way as the written program.

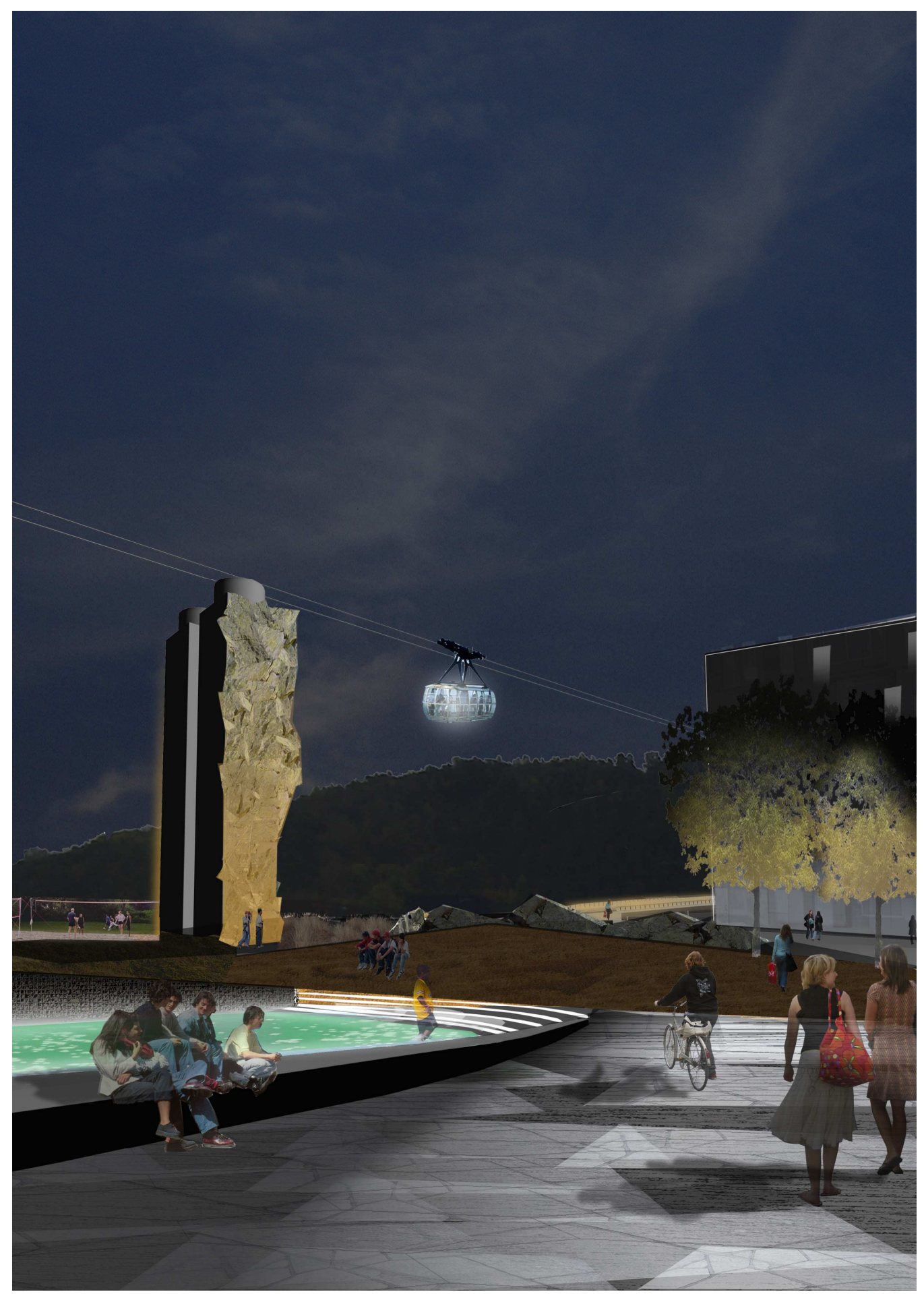

Loallmenningen, illustration by Gehl Architects, CBjørvika Development AS 
Aspen writes, "As such the seductiveness of the illustrations play an important role in making the public believe that there are serious plans for truly public places. They play a major role as legitimizing authority for the whole waterfront redevelopment" (2012, p.8). The imagery produced seems to solve the complex social issues of contemporary public spaces, quite simply, by refusing to render them visible. Therefore, one can claim, that the future commons are strategically structured in a regime of visibility.

The reductive character of the images of the public space program have the exclusive character of branded images and are, as pointed out by Evans, constructed as unified versions of complex realities. Their deficiency is in their incapacity to incorporate the internal feelings of a place and empirical based narratives. Specifically, although the illustrations offer a stereotypical and easily recognized image of leisure, they lack critical, empirical attention and consequently conceal the complex urban reality as well as the existing social dynamics. Aspen explains in his article why he is skeptical of the depictions, "All this makes me quite suspicious. Not necessarily because the new waterfront won't look as depicted when finished [...], but precisely because it just might become what is imagined!" (2012, p.4) The role of images in the distribution of the sensible and the construction of regimes of visibility is worth attention so that one can better understand their relationship to the construction of our commons. Given the strong impact of the sense of sight in spatial production, it is relevant to investigate how or when the visual generates possibilities rather than reproducing stereotypes. Urban theorist, Julian Petrin, wrote on the question of perception of space in contexts where the complexity and scale make mediated images of what is not directly perceptible, necessary. The increased influence of the current mediatized processes on spatial production and urban development motivates the study:

Put in simple terms, planning is focused on structures that generate images, since this is the only way to ensure visibility within the matrix of locational completion. The media shapes the perceptual habits and "consumption patterns" of the city, but media also represents the hurdle that urban space must successfully negotiate. (Petrin, 2008, p.160)

In this quotation, two factors are put forward; on one hand, the way in which planning relies on images, and on the other, the effect that mediated images have on our perceptual habits and thus the way we interact with space. Petrin suggests that mediated images are a constant backdrop to our interaction with material space and consequently that the patterns of our use of the city are influenced by images. He claims that immediate perception and mediated perception often overlay each other and you see what you already know is there. When the mediated images are built on stereotypes, they tend to channel broad mainstream practices and thus confirm and stabilize conventional mental images. This reflects upon the perception of material space (Petrin, 2008, pp.163-164). It is exactly this point that Petrin makes on the dynamic potential of the relationship between image and material space, when he argues for the need of "spatial stimulation." Innovative visualization practices have the means 
to stimulate space by creating disruptions in the mechanisms that reproduce easily legible, spatial images (Petrin, 2008, p.165). Petrin encourages the critical use of images in urban development, so the process of "building with images" can have an innovative role, and make the invisible possibilities of space visible and legible, rather than confirming conventional, mental images. In the following images, an epistemological figure, which teaches us a certain way to see space, is outlined; however, Petrin's analysis also indicates an ontological aspect of the role of images, as he argues that spatial stimulation uncovers otherwise unknown potentials.

\section{The Robin Hood-Strategy}

In images discussed thus far, I have attempted to show that the strategic construction of the visual representations of Bjørvika have agency upon spatial production and that the images can also be read in relationship to what they render invisible. I suggest that the distribution of a selected and thoroughly designed set of images is contributing to the configuration of Bjørvika in the public sphere and that the images are constructed as coherent narratives that do not encompass spatial and social complexity. The conflicting interests of the inhabitants of Gamlebyen and Grønland, with the economically attractive classes targeted by the stakeholders, are concealed in the coherent narrative of the constructed imagery. The unease, expressed by Aspen, on the notion that stereotypical imagery should slip into real space, affirms the nomadic quality of the images, as pointed out by Belting. As a means of spatial stimulation and the apparent shortcomings of the images to express complexity in the context of Bjørvika, Petrin's approach to the images suggests the necessity of infusing the visible narrative of Bjørvika with images that can enlarge its visible representation and negotiate complexity and empirical experiences into the public image. In 2005, the artist Marianne Heier did exactly this, by addressing the cultural image construction for the sake of marketing Bjørvika. Through the critical stance of the artist toward image-building and her use of visual terms to describe her own artistic methods, the artistic approach plays with the construction of visibility in an early phase of the redevelopment.

Heier's intervention, “A Drop in the Ocean," was done on invitation from the stakeholder Bjørvika Development (BU). Thereby, one can note that BU met the KOP-document's recommendation to accommodate cultural activities during the construction phase of Bjørvika (Planog bygningsetaten et. al., 2003, p.15). I rely primarily on Heier's text, “A frame around reality," in which she describes her approach and reflects on her own methods in this particular project. Heier is aware of the expectations of an economical spinoff effect from the cultural investments and hesitates to accept the invitation from Bjørvika Development. She writes:

It is impossible to avoid contributing exactly with what they want you to: making sure the audience associates the area with cultural and artistic activities. In a certain sense you could even say that the edgier and more aggressive you are, the better: It would just make the audience more curious, and make the area appear edgy, bold and even trendier. (Heier, 2006, p.2) 
Heier outlines the economic structure in which she, as an artist, will participate, and delineate the increase of value that the association with art has on the real estate market. The logic of place marketing becomes a central component in Heier's intervention. Bjørvika is branded as the "The Fjord Town" and Heier's work informs the constructed image of the brand with a situated meaning of what it implies to be a location close to the fjord. Historically, Heier reminds us, the proximity to the fjord contributed to a high risk of drowning, and part of the social democratic project was to construct swimming pools and provide swimming lessons to decrease that risk. Her answer to the underscoring of Oslo as "The Fjord Town" was is to investigate the condition of swimming pools and swimming ability in the city. In 2003, only $2 \%$ of the pupils in Oslo received swimming lessons, while the national average was $46 \%$ (2006, p.4). Heier's approach is motivated by the shortcomings of the municipality of Oslo in facilitating the swimming education of its inhabitants.

I chose to focus on the notion of the value and meaning of the notion "Fjord Town" and I decided to try to adopt a sort of "Robin Hood-strategy" to the situation. I would try to "steal from the rich (in this case Bjørvika Utvikling AS [Bjørvika Development]) and to give to the poor" (the increasing impoverished municipality of Oslo). (Heier, 2006, p.2)

The established strategy captures an economic relationship between the municipality and the stakeholders, and plays on the value of the branded image, as well as the value attached to the art. However, the approach also forms a spatial figure by putting forward a tension between, on one hand, the east side of Oslo and its suburbs where the largest quantity of economically vulnerable families live, and on the other hand, the large investment around the waterfront branded as "The Fjord Town." The flux of value is perceived as floating through space toward the waterfront. A negotiation starts on the character of the actual artwork, and the original plan of Heier was to make Bjørvika Development finance the refurbishing and reopening of Sagene Public Baths, owned at the time by Oslo Council. ${ }^{14}$ However, the cost of the operation would have exceeded the total art budget of the Bjørvika Development and it was not accepted. As a response to the rejection of the original idea, the project took another turn and was realized as an intervention in three different locations: the Sagene Public Bath, the waterfront of Bjørvika, and as an ad in the newspaper Morgenbladet. The publically inaccessible Sagene Bath was reopened for a day on the $25^{\text {th }}$ of June. Meanwhile, large photos of empty swimming pools from the suburbs were put up in Bjørvika. Since it exposes a potent relationship between the site of construction and the photos taken by the artist, I will focus on this intervention.

As Heier arranged to photograph the pools, she discovered that many of them were closed the majority of the time (2006, p.5). Consequently, the physical reality of the municipality of Oslo's shortcomings in providing public baths was made known to her.

\footnotetext{
${ }^{14}$ The building was to be sold for a symbolic amount if the buyers restored it.
} 


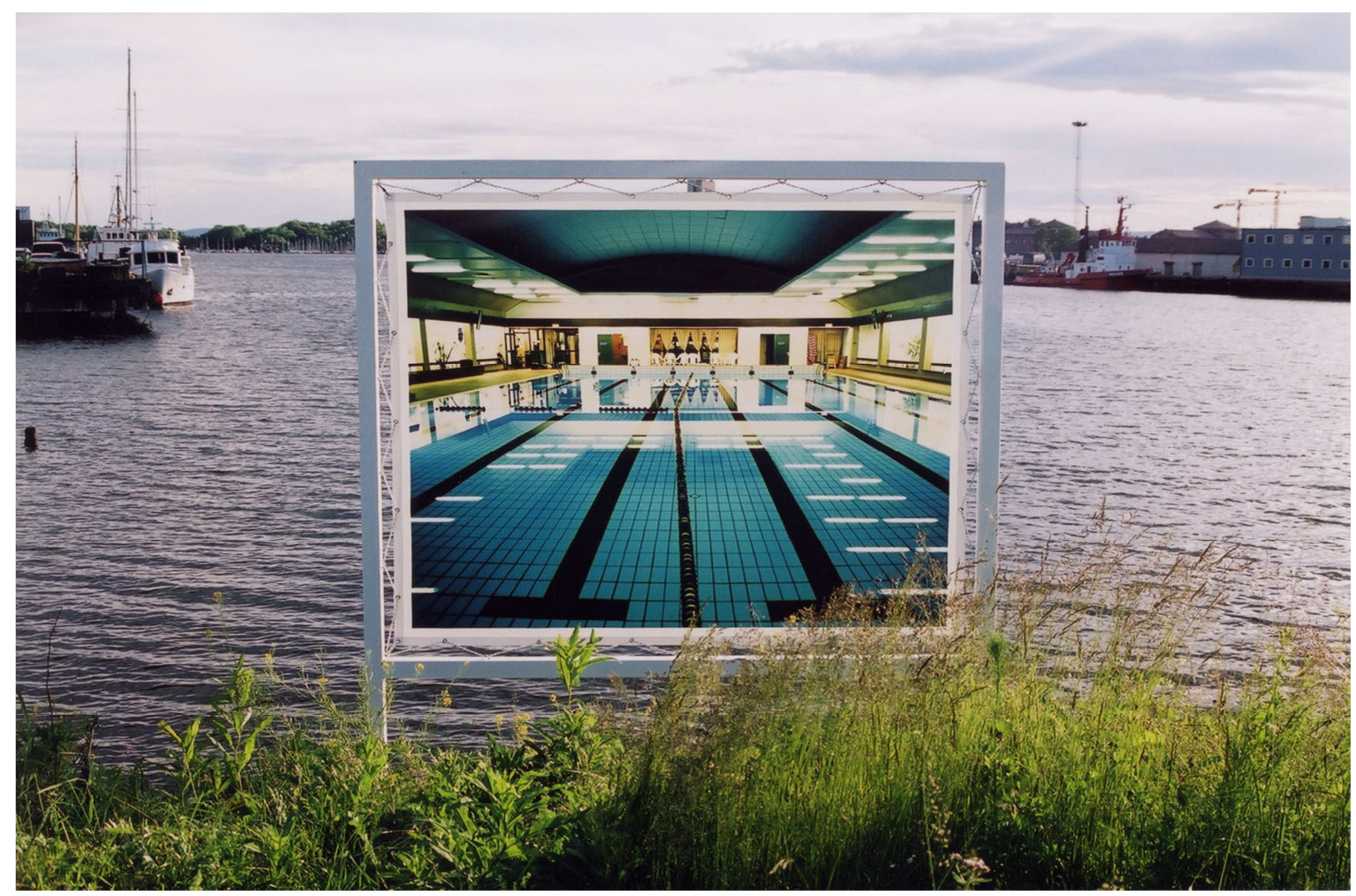

Marianne Heier, A drop in the ocean (2005). The photo of Holmlia public bath was placed on the site of the future Loallmenningen.

"A Drop in the Ocean" introduces counter narratives to the unified version of the branded image of the "The Fjord Town." The question of who and what is represented, is put forward through the critical investigation of what substances can be played into the notion of "The Fjord Town." Heier's research, along with the documentation of the empty public pools, infuses the general process of making Bjørvika visible with images that mediate experiences anchored in local, internal, and economic realities. On one side, whether she wants to or not, one can easily agree with Heier's analysis of the artist as a contributor in the gentrification of the area. However, her critical approach to the image of the "The Fjord Town," can also be said to negotiate the visible representation of Bjørvika by rendering visible what was previously unseen. In a certain way, because of the way it problematizes the simple and unified narrative of "Fjord Town" and operates in accordance with Evans and Mommaas' critique of the image-building of places, the intervention is a counter-image to the branded image. If the circulating images have agency upon spatial practice, and the processes of development are staked out by images, the question of who is represented, along with the visualizations of local empirics, becomes important. In concurrence with Rancière's theory of the distribution of the sensible, I believe that sensorial experiences that transgress boundaries and divisions instituted through a perceptual regime can have an ontological dimension and affect not only our ways of seeing, but also our ways of doing. Marianne Heier's intervention puts forward interests and experiences, which otherwise would have been invisible. By placing the large boards of empty swimming pools along the 
waterfront, Heier was putting up literal images in the future commons and distributing other aspects of Bjørvika that were yet to be seen.

Rancière argues, as we reminds ourselves, that the work of artists has the potential to open new forms of visibility and thereby recompose the landscape of the visible (2000, p.72). Although central to this paper, to what extent art recomposes the general landscape of the visible, or only the landscape of visual art, is a difficult question. Rancière wrote the following on the dissensual practices of politics, "It thus necessarily confronts the blindness of those who 'do not see' that which has no place to be seen" (2010, p.39). Tentatively, one could propose that art has the visual means to confront institutionalized blindness.

\section{New Eyes or New Forms of Visibility}

The question remains, when does art affect the regime of visibility and more precisely, how is "A Drop in the Ocean" attempting to open new forms of visibility in the representation of Bjørvika? Even though the materiality of her work is not strictly visual, Heier applies visual terms to describe her artistic tools and the mechanisms that she manipulates. In her art practice-based doctoral thesis, Marianne Heier writes that she looks for "blind zones" that are lost in simplifications and that they constitute the starting point of her works (2013, p.6). When she introduces physical, concrete elements in a chosen environment, she attempts to activate overlooked potentialities. In her reflection on the intervention in Bjørvika, visual terms are also used to describe the goals of her own practice.

Through this process, the artist takes on a temporary ownership and responsibility of actions and experiences taking place within the frameworks of the situation defined as "art". [...] When the strategy works, it opens up for situations to appear as new and different; as never seen before. It provides new eyes. (Heier, 2006, p.1)

The strategic goal of "A Drop in the Ocean" was to provide new eyes and open the situations to appear as never seen before. I will suggest that the visible is modified in two steps: first, the artist, through thorough research, sees the situation as it has not yet been seen; second, the situation can appear to others as new. Specifically, the artist proposes an anonymous public spectator to see with "new eyes." One can argue that the object of the artistic touch is the gaze of the beholder. The assumption that the gaze is determinative of how a situation is perceived and that there are blind zones within our visual culture, concurs with Rancière's identification of a regime of visibility. However, the formation of a new collective way of seeing can be approached by the relational aspect of the skilled perception, coined by Daston as seeing collectives. Nonetheless, before closing on this issue, I will attempt to describe the workings of the "new eyes" that Heier provided.

During the summer of 2005, the photos of empty swimming pools were displayed along the waterfront of Bjørvika. The concrete and physical object through which Heier attempts to stimulate an overlooked potential has its own striking visuality. However, the photos are not the objects that need 
to be seen with new eyes. Instead, it is the surrounding reality and the constellations of which the empty swimming pools are a product, which Heier puts forward to be seen. So what happens to the gaze of the passer-by along the waterfront? It is quite concretely redirected. By redirecting the gaze from the waterfront to the suburbs, the emplacement of the photos in Bjørvika reconfigures a portion of the visible. If one agrees with the logic of place marketing and the assumption that visibility increases economic value, the gaze has an economic value and the redirection of it is a redirection of value. One could read the valuable gaze as moving upstream and in the opposite direction of the general money flux. This interpretation suggests that Marianne Heier's Robin Hood-strategy works. As difficult as it might be to answer, the question of efficiency remains. Whether the critical and analytical approach of Heier was encountered as such, or absorbed as a cultural event, is also a question for the audience. ${ }^{15}$ In a case such as with Bjørvika, negotiating the image of the city is also to negotiate which parts of the population one addresses. If the gaze proposed by the artist comes to be shared by many, it can be identified as more than a symbolic gesture. The ambition of the artist to provide new eyes can be rephrased, as to skill her spectators' gaze, so that they see what they used to overlook. How the seeing collectives, studied by Daston, were established despite professional, linguistic, and cultural differences is thought-provoking because differences of that order are not easily transgressed. One of the challenges of the urban redevelopment of Bjørvika is to construct a common ground despite social and cultural differences, this challenge can also be said to account for the artist whose work is embedded in a social set of problems and wishes to reach communities trained in other perceptual habits.

\section{Final Remarks, Recomposing the Visible}

In the example of the skilling of perception in relation to the new collective way to see clouds, I touched upon the role of images, as seeing collectives are being formed. The International Cloud Atlas was the product of a compromise reached in Uppsala, and the images were pivotal in illustrating and shaping what was agreed upon as seen in unison. These images can be said to have established a new way of holding the world in common. I wish to draw a parallel from this atlas to the 3D model of Bjørvika. The atlas was the locus of negotiation, as the diverse interest and different competencesone could say different ways of seeing-attempted to reach agreements. Torbjørn Tveiten claims that the 3D model was indispensable during the negotiations of the development regulations, and that it was the primary tool for mediating the project (2011, p.236). In spite of the differences, the use of the model during the decision making process suggests the importance of the images in the process of forming a collective way of seeing.

Lorraine Daston's study on the science of clouds demonstrates how scientific observation affects the everyday perception and articulation of the visible world. However, the new way of seeing

\footnotetext{
${ }^{15}$ Heier outlines this dilemma herself $(2006$, p.5).
} 
clouds was also a result of artistic observations. The paintings of Constable and Weilbach influenced the science of clouds that was contemporary to their time. Earlier Italian painters such as Giotto, Masolino, Corregio, and Mantegna had rendered other possible shapes of visible clouds (Damisch, 2002). Just as one can identify a relationship between scientifically skilled perception and everyday perception, artistically skilled perception can influence how everyday perception is formed. The triangular schema outlining the relation between the skilling of perception, the participation in a collective, and images, defines images as influent. Such an understanding of the role that images play urges a critical approach to them. While images that mediate forms of formerly unperceived visibility might skill perception, stereotypical imagery maintains a static perception. This article have attempted to draw attention on the necessity of a critical approach to practices within urban development that "builds with images."

While Rancière identified the sensible as constitutive of the public, Daston's approach to the formation of seeing collectives provides insight as to how the plasticity of the sensible is shaped through the skilling of perception. Therefore, the term 'skilled perception' might prove helpful in the analysis of perceptual regimes. The prevalence of vision over the other senses in the redevelopment of Bjørvika calls for a more competent perception of the visible. Although opposed by artist Marianne Heier through different visual means, the seductive visuality of the waterfront, as pointed out by urban geographer Heidi Bergsli, draws attention away from other areas in the city. Images are more than illustrations, rhetorical figures, and temptations. They have an epistemological dimension through which we learn to see the world. By rendering possibilities known, images present us with what is within reach and they separate the known from the unknown. Rancière (2008) sees the access to new forms of sensibility in relationship to social and political emancipation and argues that the divisions in the definitions of the material of the sensible, which we hold in common, can be transgressed by critical art. As part of the distribution of the sensible, images can be a locus of discovery and change. They can also counteract the boundaries and divisions that exclude economic, social, and cultural forms of visibility from the public simply by not representing them.

\section{On the contributor}

Charlotte Blanche Myrvold is currently Ph.D.Candidate at Oslo and Akershus University College of Applied Sciences/The Oslo School of Architecture and Design. She holds a MA degree in aesthetics from the University of Oslo. Her research subject is public art in urban redevelopment contexts.

\section{References}

Aspen, J. (2013). Oslo- The triumph of zombie urbanism. To be published in R. el Khoury and E. Robbins (Eds.), Shaping the city: Studies in history, theory and urban design, New York: Taylor and Francis/Routledge. 
Belting, H. (2011). An anthropology of images (T. Dunlap, Trans.). Princeton: Princeton University Press.

Bergsli, H. (2005). Entreprenørpolitikk og byutvikling. Byutvikling og globale trender. In J. Aspen (Ed.), By og byliv i endring. Studier av byrom og handlingsrom i Oslo (pp. 87-120). Oslo: Spartacus Forlag.

Brenna, B. (2012). Om å innrede med landskaper. In N. F. Høyum \& J. K. Larsen (Eds.), Utsikter: Norge sett fra veien 1733-2020 (pp. 12-21). Oslo: Forlaget Press and Nasjonalmuseet.

Böhme, G. (1998). The atmosphere of a city. Issus in contemporary culture and aesthetics (April 1998), 5-13.

Böhme, G. (2008). "Innføring.” Fra Aisthetik. Vorlesungen ûber âsthetik als allgemeine Wahrnehmungslehre (A. B $\varnothing-$ Rygg, Trans.). In A. B. Bø-Rygg, K. (Ed.), Estetisk teori. En antologi. (pp. 519-532). Oslo: Universitetsforlaget.

Damisch, H. (2002). A theory of cloud. Toward a history of painting (J. Lloyd, Trans.). Stanford: Stanford University Press.

Daston, L. (2008). On scientific observation. Isis, 99(1), 97-110. http://dx.doi.org/10.1086/587535

Daston, L., \& Lunbeck, E. (Eds.). (2011). Histories of scientific observation. Chicago: University of Chicago Press.

Evans, G. (2006). Branding the city of culture. The death of city planning? In J. Monclús \& G. Manuel (Ed.), Culture, urbanism and planning (pp. 197-214). Hampshire: Ashgate.

Gran, A. B., \& De Paoli, D. (2005). Kunst og kapital: nye forbindelser mellom kunst, estetikk og naringsliv. Oslo: Pax.

Grasseni, C. (Ed.). (2007). Skilled visions: Between apprenticeship and standards. New York: Berghahn.

Heier, M. (2006). A frame around reality. Retrieved May 27, 2013 from http://www.cornercollege.com/udb/cproAFsxBRA_Frame_Around_Reality_-_Marianne_Heier.pdf

Heier, M. (2013). Ex centric. (Art practice based doctoral thesis, distributed on May 19, 2013 during the defense of the doctoral thesis).

Jones, C. A., Galison, P., \& Slaton, A. (1998). Picturing science, producing art. New York: Routledge.

Klonk, C. (1996). Science and the perception of nature. British landscape art in the late eighteenth and early nineteenth centuries. London: Yale University Press.

Kotler, P., Asplund, C., Rein, I., \& Haider, D. H. (1999). Marketing places Europe. Edinburgh Pearson Education Limited.

Mommaas, H. (2002). City branding: The necessity of socio-cultural goals. In City branding: Image building \& building images. Rotterdam: Simon Franke.

Petrin, J. (2008). Stimulating the second space. In A. Thierstein \& A. Förster (Eds.), The image and the region - making mega-city regions visible!. Baden: Lars Müller Publishers.

Plan- og Bygningsetaten, Oslo Havnevesen, Eiendoms- og byfornyelsesetaten, Statens vegvesen region øst, Statsbygg \& ROM Eiendomsutvikling AS . 2003. Barekraft i Bjørvika:

Kulturoppfølgingsprogram. Retrieved April 4, 2013 from http://www.statsbygg.no/FilSystem/files/prosjekter/bjorvika/kopBjorvika.pdf

Rancière, J. (2004). Malaise dans l'esthétique. Paris: Galilée.

Rancière, J. (2008). Le spectateur émancipé. Paris: La fabrique.

Rancière, J. (2010). Dissensus. On politics and aesthetics (S. Corcoran, Trans.). New York: Continuum.

Rancière, Jaques. (2000). Le partage du sensible: Esthétique et politique. Paris: La fabrique-éditions. Sennett, Richard. (2008). The craftsman. Yale University Press, London.

Tveiten, T. (2011). Bjørvika. Bruk av \#D i planarbeidene. Kart og Plan, 71(4), 235-240. 